Dr Adéle L Moodly

Rhodes University, South

Africa, Email: a.moodly@ru.ac.

za

Dr Noluthando M Toni

University of Fort Hare, East

London, South Africa, Email:

ntoni@ufh.ac.za

DOI: $h$ ttp://dx.doi. org/10.18820/2519593X/pie.

v35i2.12

ISSN 0258-2236

e-ISSN 2519-593X

Perspectives in Education

2017 35(2): 155-167

(c) UV/UFS

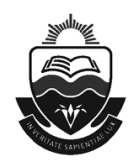

\section{Re-imagining higher education leadership - in conversation with South African female deputy vice-chancellors}

\begin{abstract}
Part of the decolonisation and transformation of higher education institutions is the re-construction of its leadership. This requires not only a review but also a dissolution of traditions, conventions and organisational forms that universities have inherited, including a reimagining of leadership in higher education. Equity in representation of women in leadership has been acknowledged locally and internationally as part of the transformation agenda towards sustainable leadership. The authors argue that decolonisation and transformation are not mutually exclusive processes in the South African context, but that transformational leadership is part of the decolonisation process. This should embrace women's ways of leadership in reconstructing leadership. The paper reflects on empirical data from personal interviews with three deputyvice-chancellors on their journeys to leadership, with a focus on psychological and cultural factors (at the micro and meso levels), their career-pathing, personal characteristics and their experiences. These experiences are considered in the context of literature on women and leadership, using critical discourse analysis. It gives insight into the pathways that women often follow and provokes us to re-imagine the construct of "leadership". The paper concludes with recommendations on the impact of psychological and cultural factors and the importance of the implementation of transformative policies, affirming male and female role models, institutional support structures and career planning which should form part of the decolonisation and transformation of conventions in capacitybuilding towards equity and sustainable leadership.
\end{abstract}

Keywords: Transformational leadership, decolonisation, personal life experiences, women's journeys

\section{Introduction}

This paper is one of a series of papers (Moodly, 2015; Moodly \& Toni, 2015a; 2015b; 2017) on women in higher education leadership. The purpose of the research was to review women's personal life experiences reflecting on what literature has indicated as factors that influence women's ascension, or lack thereof, to senior management leadership in universities. Internationally, as well as in South Africa, the lack of women in positions of leadership in all spheres of society has been acknowledged, despite women constituting the majority of the population in most countries (Chanana, 2013; Bulick \& Frey, 2017). Historically 
and traditionally, leadership has been the preserve of men, as attributed to and perpetuated in the patriarchal nature of society. In South Africa, the legacy of apartheid contributed to the oppression of women from a gendered as well as a racial perspective in all spheres of society. Legislation to address these resultant inequities, manifested in amongst others, Education White Paper 3 (Republic of South Africa, 1996) the National Plan for Higher Education (Department of Education, 2001) and the Women Empowerment and Gender Equality Bill (Republic of South Africa, 2013). Despite these initiatives, research reflects that women in Higher Education have been stuck at middle management level. This situation is attributed to various factors. These include but are not limited to the glass-ceiling, the lack of mentors, gendered organisational culture, a culture of service and caring leadership, prioritising family life, non-linear and non-chronological pathways in career-pathing, a lack of role models and lack of support by top management in a patriarchal organisational setting (Chanana, 2013; Nguyen 2013, Grimshaw \& Francis, 2014). South African women, as is the case internationally, have increasingly accessed higher education, reached middle management positions, yet are unable to break through the upper echelons (Shambare, 2011; Chanana, 2013; Shevel, 2014; Bulick \& Frey, 2017). In her research on barriers that inhibit women's leadership progress, Nguyen (2013) points to psychological walls and cultural barriers that inhibit women from aspiring to leadership. She cites Cubillo and Brown's (2003) three levels from which cultural barriers emanate, namely the "macro" socio-political level, the "mesco" (more widely known as the meso environment) organisational level and the "micro" individual level.

There are also women who have broken through the barriers (Chanana, 2013). The focus of this paper was to review the cultural at micro and meso levels and psychological factors at micro level associated with women's experiences towards leadership and to ascertain whether these experiences were reflected in the three women's journeys and to possibly identify areas of commonality that enabled them to attain their respective senior management positions.

\section{Transformational leadership towards addressing social injustices: A theoretical framework}

Badat (2009: 455-456) distinguishes between "change" and "transformation" in "theorising" change. He advances that "change" does not necessarily imply "substantive changes in established policy, practice or organisation" more than being limited in scope in respect of intent and nature. Transformation contrastingly, speaks to "intent" to dissolve existing social relations and institutions, policies and practices and their recreation into something substantially new. In re-imaging leadership, the authors adopt the construct of transformation in the former context. Traditionally, leadership has been viewed from a male-gendered perspective, hierarchical in nature with mostly men in leadership roles, including educational leadership. The stereotypical characteristics of leadership as perpetuated within society were that of a single person wielding power and authority, with "hierarchical control over people" (Muzvidziwa, 2015: 366). This bureaucratic approach has been contested, with contemporary views leaning towards communication, moral responsibilities, caring and mutual support (Muzvidziwa, 2015). Women reflect these transformational leadership practices in their manner of involving others, nurturing and encouraging participation in collective decision-making (Sinclair, 2012, as cited in Muzvidziwa, 2015). "Empowerment of followers" is seen as a key component of women's transformational leadership practice (Kark, 2004 as cited in Muzvidziwa, 2015). Muzvidziwa (2015: 368) quotes Bass (1985) in identifying four components of "transformational leadership theory", namely, "idealized influence, inspirational motivation, intellectual stimulation and 
individualized consideration". Transformational leadership is not gender-specific, but can be reflected in male and female leaders who focus on the "development and empowerment of followers to function independently and effectively" (Muzvidziwa, 2015: 368).

\section{Decolonisation and transformational leadership: Is there a link?}

The trajectory of the South African higher education environment towards transformation (addressing inequities and redress) and decolonisation demands a re-imagining of leadership in this context. The authors are of the view that decolonisation cannot be isolated from transforming leadership; and that transformational leadership is a catalyst (amongst others) for the decolonisation process. Decolonisation is contextualised as being about "justice" as championed by the likes of Frantz Fanon and Edward Said (cited in Pillay, 2013). Pillay's (2013) construct of colonialist ideology as the "devalorisation of intellectuals, of thought, of knowledge and aesthetics outside the Western tradition as constituted in the modern disciplines around which the university is structured" is extended in this paper. In this paper it includes the "gendered cultures" (Grimshaw \& Francis, 2014:211) of university environments as constructed through the colonialist ideology, valorising a Euro-American construct of leadership. It is argued that transformational leadership interrogates the valorisation of the Western tradition of leadership towards social justice.

Becker (2017:6) on reflecting on how the hashtag (\#) movement in the South African (SA) HE sector of 2015/2016 could "inform rethinking of transformation" in the SA HE context, argues that our reality, rather than being constant, is changed and reframed (as was depicted by the protest actions). Becker cites Zizek (2014) in arguing that transformation is continual and embraces "ethical transformation" ("a good way of being"). Further, "ethical transformation" should view "subjects of HE" as "irreplaceable and unique". In this sense, a paradigm shift and "reconstitution of the psyche" becomes important. It is through this process that decolonisation, amongst other important elements, can be engaged.

\section{Statement of the problem}

The introduction outlines that literature continuously reflects that psychological and cultural barriers at the micro and macro levels (amongst others) affect women and that these influence their lack of aspiring towards higher education leadership. Moodly (2015) and Moodly and Toni $(2015 ; 2017)$ argue that there is a need for women as role models in leadership in higher education, citing equity and social justice for the basis of their argument. This demands a reimagining of leadership as part of the transformation process, by introducing women's ways of leading into the leadership space. The authors argue that re-imagining leadership forms part of the decolonisation process (as outlined further on in this paper), the former acting as a catalyst for the latter. Given that proportionally, in the South African context women outnumber men (Republic of South Africa, 2017); this has a multiplicity of implications for, amongst others, the socio-economic viability and sustainability of the country. Should women therefore, not be capacitated and developed as part of the labour force, including strategic leadership within various sectors of the South African society, the ramifications are dire. This, in conjunction with the principles of equity within a just and democratic society, is imperative towards acknowledging women in all spheres, including higher education leadership. Principles of transformation as per the country's national agenda, as previously mentioned, affirm the recognition of women in all spheres and levels of society. As Moodly (2015) and 
Moodly and Toni (2015) argue, there is a need for women as role models to inspire women towards leadership. However, currently, these role models are few, but do exist. There are currently women in South African higher education executive leadership. The focus of this paper is to gain insight into what inspired these women towards their positions, given the barriers that face women, with specific reference to psychological and cultural factors at the micro and meso levels, as outlined in the literature. The paper focuses on the women's personal journeys towards higher education leadership, with specific reference to the impact of the aforementioned factors, towards re-imagining higher education leadership.

Given the introduction as outlined, the following research question was posed:

How can the re-imagining of higher education leadership be facilitated considering factors at the micro and meso levels that influence women and decisions towards higher education leadership?

The sub-questions in this regard, which also serve to expatiate the aim of the study, are:

1. What are the psychological factors that influence women's decisions on leadership?

2. What are cultural factors at micro and meso levels that influence women's decisions towards higher education leadership?

3. How can women advance towards higher education leadership?

\section{Purpose of the study}

The study explores psychological and cultural factors at women's micro and meso levels respectively, that influenced their decisions towards higher education leadership, despite barriers as highlighted in literature. It focuses on these factors to understand what micro-level characteristics facilitate women's advancement in overcoming barriers. The women in this study have attained executive leadership in higher education and insight into their journeys may contribute to the body of knowledge in addressing these challenges in re-imagining higher education leadership.

\section{A review of the literature}

Nguyen (2013) identified push and pull factors in terms of women's experiences in advancement to leadership and management positions. For example, psychological factors affected by "negative gender stereotypes" may impede advancement. The "ingrained barrier" of women as "more communal" in contrast to "more agentic" men (seen as having the qualities for management), has resulted in the questioning of women's ability to lead (Nguyen, 2013:124-125; Grimshaw \& Francis, 2014). Cultural barriers include "hegemonic cultural traditions" of women taking more family responsibilities than men, and even in situations of partnering, domestic responsibilities were still disproportioned, with the expectancy that women take on a larger portion. Cultural traditions also influenced women's broader social behaviours, often-times as submissive and quiet. Acting out of expected character, could lead to embarrassment for the family (as in the Vietnamese tradition). The "meso" level reflects the barrier of universities' "highly masculine culture". The "balance of power" still favours men, manifesting at times in inequalities in remuneration and advancement (Nguyen, 2013:126; Grimshaw \& Francis, 2014). 
The extent to which women internalise cultural traditions at all levels (micro, macro and meso) may affect representation in management and leadership. What seems to facilitate women's advancement are "personal factors, family support and mentor support" (Nguyen, 2013). Personal factors reflect self-motivation, independence, being a hard worker and confidence. Family support included help from extended family members and partners and a strong father influence (Turner, 2007, Cubillo \& Brown, 2003 as cited in Nguyen, 2013). "Mentoring" by senior leaders "who support women" and "networking" advanced careerpathing into leadership and management. Nguyen (2013:128) also cites various authors, in highlighting lesser-known factors that have facilitated women's advancement. These include "early educational and career success", "teachers' inspiration", "administrative career advancement", accepting "an interim position", as well as "adopting non-traditional leadership styles".

The gendered nature of universities, which has led to disproportionate representation of women in leadership, was a catalyst to the vice chancellors' organisation of Australian universities discussing how to identify women who aspire to future career pathing in leadership and to increase representation. This is also reflected in a broader context through the "Workplace Gender Equality Act" (2012) passed by the "Labor Government" (Grimshaw \& Francis, 2014). In the South African context, Moodly and Toni (2017) suggested the MoodlyToni framework towards implementing gender equity in higher education leadership. This framework highlights a phased-in approach and interventions at each phase in support of women in career-pathing towards leadership. It lends itself to facilitating the re-imagining of higher education leadership, in advancing and capacitating women through various phases of their respective careers.

\section{Methodology}

The primary method was face-to-face interviews, which were transcribed and sent back to the interviewees for corrections and comments. The phenomenological interpretivist approach guided the research, focusing on each "individual's unique interpretations of her lived world" (Grant 2005 as cited in Muzvidziwa, 2015: 369).

\subsection{Analysis of data}

Critical discourse analysis (CDA) was used to carefully reflect on the responses to questions and any nuances that presented themselves. CDA as explained by Hammond (2006:550) is the viewing of "discourses as not only constructed by social practice, but also as constitutive of it". Hammond cites Wodak (1995: 204), in stating that a critical objective (of CDA), is to analyse both "opaque" and "transparent" "structural relationships of dominance, discrimination, power and control as manifested in language". CDA reviews "ideological assumptions that have become accepted and concealed" which in turn "are interpreted and explained in terms of the wider social practices that shape discourses and that are shaped by them"(Hammond 2006:550).

The researchers reviewed and reflected on all responses and had intense discussions, having individually reflected on questions and responses as part of the CDA, before comparing views on the responses. Themes were then identified in line with literature themes that had presented themselves in the theoretical phase of the study, as reflected in Moodly and Toni (2017). New themes that presented themselves were also recorded. The write-up of findings was in the format of themes identified, together with a reflection of the literature that reflects 
the theme. This allowed the participants' personal voices to come through in the paper, so as not to lose the rich data. The responses were analysed in terms of the theoretical framework of transformational leadership towards addressing social injustices, foregrounding women's voices and experiences that influenced their decisions on, and styles of leadership in higher education, navigating the gendered spaces of HEls. Their voices speak to their own, personal journeys that assist us in re-imagining leadership as a means of correcting social injustices and decolonising the construct of leadership, through elevating traditions and practices that are inclusive of women's ways of knowing and doing. When reflecting on participant responses, participants are referred to as Participant $A, B$ and $C$ as a form of anonymity in line with research ethics.

\subsection{Population and sampling}

The target was women at the level of Deputy Vice Chancellor and Vice Chancellor at South African universities. Of a population of women within these positions in 2016 , the researchers wrote to seven, of which the three whose journeys are reflected in this paper responded and were able to make themselves available for the engagements. As the research was carried out during the volatile period of the RhodesMustFall and FeesMustFall protest actions of 2016 (Jansen 2017), it was difficult for all participants who had initially agreed to be part of the research, to commit to interview dates.

\subsection{Profiles}

In line with confidentiality and protecting the anonymity of interviewees, it is only revealed that the DVCs were women within the age ranges of $40-60+$, and across the race diversity. All three occupied DVC positions at South African universities across two of the university types, namely traditional and comprehensive, of which two were former historically disadvantaged institutions (HDIs). Moodly and Toni (2017) have outlined that the number of women in the position of Vice Chancellor (VC) had declined by almost two per cent between 2014 and 2016 .

\section{Limitations of the study}

Only three women were interviewed and their journeys profiled. The findings can therefore not be generalised to all women in leadership positions at South African universities. The impact of race, transgender and alternatives to the traditional view of the family has not been explored in this research. These might bring in dynamics that may influence the data, analysis and interpretation thereof, had they been considered in the research.

\section{Findings}

The findings are presented according to themes as revealed around the psychological and cultural factors at the micro and meso levels, and are discussed in relation to pertinent literature.

\subsection{Psychological factors at the micro-level}

\subsubsection{A passion for studies, uncertainty and teaching}

The findings reflect that there were particular choices in the initial career choices of the three participants, though not necessarily for work-family balance reasons. The career choices were based more on the uncertainty of career pathing. All three women studied in the Arts and hold bachelors' degrees. This was their first step into their respective careers, which coincidentally were as teachers and then onto lecturers with Language backgrounds (English 
Literature/Applied Linguistics), at various South African institutions. Respondents reflected a "passion" for the choice of studies. They also expressed a self-determination to further their studies after completing their secondary/high schooling. Respondent B expressed, "I really ... wanted to have a higher education experience ... an academic experience". Teaching was not necessarily their first choice of career, but due to uncertainty about their career-pathing after completing their first degrees, they started as teachers. Participant A indicated that she was a "latecomer to higher education" having completed her Master's degree and "couldn't think what to do with myself". She then went into teaching and hit a barrier when she realised that she was "never going to ... get any sort of promotion positions". Participant A also expressed that she knew she "didn't want to teach" but that she taught internationally nonetheless. She then decided to continue her studies, with a second Master's degree. Participant B expressed; "I didn't want to be a high school teacher, I wanted to teach at university level".

Findings tend to perpetuate the literature which reflects that women tend to socially prescribed work as previously indicated, such as teaching and nursing and moving on to occupy leadership positions traditionally. There remains a need for women to broaden into professional disciplines to extend access to leadership in other spheres (Grimshaw \& Francis, 2014). Literature states that women follow specific career paths for various reasons, in particular linked to work-family balance, with teaching and nursing the most common choices (Nguyen, 2013; Johnson 2014 cited in Moodly \& Toni, 2017).

\subsubsection{Doctoral studies, intrinsic motivation and seizing opportunities}

Having a $\mathrm{PhD}$ also stood all three women in good stead at a time when most black academics (men and women) and especially women (of all race groups) did not have PhDs. This opened access to leadership more easily, especially in the middle management areas. Their qualifications at the time, coupled with their passion for their work, saw all three women move into middle and eventually into senior management positions. As previously mentioned, part of their experience also came through their involvement beyond academic work such as lecturing and publishing, (running projects, writing reports, involvement in student affairs and consultancy).

Respondents $A$ and $C$ moved into the positions of Dean, with participant $C$ also having been a Departmental Head, onwards to Deputy Vice Chancellor. Significantly, as indicated in literature (as previously mentioned), the pathway was in the areas of teaching and learning and/ or student administration, rather than research. They came through academic ranks of Faculties in the Social Sciences and Humanities, rather than the Pure Sciences and Mathematics. Research output played a significant role in Participant A's career-pathing, indicating that "as my work began to be reasonably well received, that really built me as a person .... and it gave me a completely new sense of myself, a completely new identity ... and so I continued". Through "affirmation" Participant A wanted to do "more and more academic work" which "pushed me into more research and ... publishing". She could not remember, "consciously wanting to become a leader" but ended up "with leadership jobs in academic development because of the way that the field just works ... especially once I had a PhD". Respondent A's situation reflects intrinsic motivation to do better with extrinsic affirmation. It also confirms that research publications and a doctorate qualification are key to attaining leadership positions. However, her ascension to the position of DVC was "by chance" and she "didn't aspire to it, it came to me along the way". Having obtained her Doctorate, Respondent $\mathrm{C}$ also took up a middle management position in academia. Respondent 
$B$ also held middle management positions within the education arena, albeit not in higher education. Her experience in higher education nationally and, together with her ability to communicate effectively, saw her move to senior management positions in the education arena. She also gained experience in industry through education-industry partnerships. Her ability to keep good relations with various HEls at the same time, saw her move into a senior management position at an $\mathrm{HEl}$, where after opportunities for movement were presented. Though Respondent B had not specifically focused on leadership in an HEI, she had a focus in terms of her career; "I had my own plan". She was passionate about higher education and wanted to contribute as was previously indicated. Respondent B had not clearly planned to move through the academic ranks, but knew that she would "exhaust every career stamp ... every career level". She always "had the drive" with her career as she had with her studies. She did however reach a point where she "realised" that she was "more motivated" working with people from a "management side of things", and made a choice to focus on management at this point.

\subsection{Cultural factors at the micro-level}

\subsubsection{Family responsibility, self-doubt and choices}

Participant A expressed the view that family situations influence career advancement choices in academic management. As a single parent, her family was her priority. She was also of the view that women are their own "worst enemies" in "imagining the people we could be". She drew from her own experience indicating that she was "terrified of failing" and did not realise she had "always been good enough" until it was said to her by a male supervisor. Although she had been invited to apply for positions, she had not done so, as she lacked confidence. Participant B was also of the view that women are their own worst enemies, stating that, "we can sabotage ourselves". She stated that women make excuses "for not going to the next level", such as being "caregivers and responsibilities at home". The "extended family or inlaws" were also reasons women expressed for not advancing. Women were also "apologetic" in accepting positions, expressing self-doubt and surprise when they achieved. Women should recognise their own role in achievements, rather than the tendency to attribute their achievements to someone else. Participant B emphasised that women should have "their own plan" even if the start they got was accidental in nature. She indicated that women should recognise that they are capable of senior management positions. Applications were usually for middle management positions, where in her view, women felt "more content". Participant $\mathrm{C}$ expressed that women "have been given a lot of false choices". One of these false choices is that "you can do everything and be everything". In her view, women should consider their circumstances when making decisions to choose senior leadership positions. She cited an example to explicate that women should decide to "focus on her (their) career" or "have time for children". To do both, she indicated that, "you would look at what stage of your life" you are, as you cannot be a "leader of a Faculty which is going to require time ... to manage ... you can't do both". She expressed that women should consider the age, for example, that they would think that their children are independent enough, and thereafter "aspire" to leadership. On the other hand, women may decide that, "children are not as important" to them, that "there are choices you need to make". In her view women "dominantly ... don't necessarily apply" for senior leadership positions, based on the choice of "what role they want to play in those (their) children's lives". She believes that there are leadership roles "wherever you are" and they do not necessarily come "with seniority" but thinks that "false choices have been put to women and they burn themselves out in the process". 


\subsubsection{Leadership style - caring and service orientated}

The caring service orientation of leadership reflected in Participant B's remarks that she took up leadership positions initially at periods of transition within divisions, when someone was needed to "hold the fort" in an "area which was problematic". She was called upon, as her caring, service-orientated leadership style was known. "I was ... the motivational person, getting people back on track....the agony aunty" listening to people's complaints but trying to ...arrange things, get people to have a bigger picture". Participant A's caring came through in her response describing her leadership style as "I'll always stand up and greet them and try to make them feel comfortable. I believe I can exhibit warmth as a human being and I try to do that as much as possible ... I really try to hear what they have come about". She also expressed the importance of knowing "when a quiet word is more appropriate". Owing to her manner of leadership, she is viewed as a "person of integrity". Participant B also agreed that her leadership style was "diplomatic", "sensitive" and "constructive" with "gentle persuasion", rather than "imposing", but with the ultimate goal of getting cooperation.

\subsubsection{The non-linear/non-chronological pathway}

After short periods in teaching, the women did not necessarily remain on the academic trajectories towards higher positions. All three left teaching or academia at some stage and pursued other interests (in administration, community projects and consultancy) before resuming careers in mainstream academia. Participant $A$ left teaching when she realised she was not being promoted, did a second Master's degree and joined a project at a South African university. Participant B taught for a few months and thereafter changed career-path, during which time she secured an international scholarship and pursued her studies. Her family responsibility also saw her make a further career change for a period of time before she refocused on her career and applied for a position in which she was interested, in an educational organisation. She actively enquired about posts in education, as she "really loved higher education". Participant C also left mainstream academia, though she kept strong links with higher education institutions (HEls), being involved in numerous projects that developed good working relations within the HEl sector. Women's career pathing is not always chronological and linear (Chanana, 2013; Moodly \& Toni, 2017), and this is reflected in the journeys of the three women.

\subsection{Cultural factors at the meso level}

\subsubsection{Influence of role models}

Role models, in the form of men and women, influenced the career-pathing and motivation of all three women in terms of going beyond teaching at high schools, to further their studies, as well as to take up posts other than teaching. After reading a research report written by participant $A$, a teacher observed that she should do her Doctorate and requested her proposal. "I'd never considered myself as PhD material, so I think the request from this woman whom I considered an absolute guru (expert in the field of research) ... bowled me over." After a number of publications from her Doctorate, she was "invited to apply" for a senior management position at a university. Participant B wanted to become a lecturer when she was an undergraduate student at university, but "had never seen a black person teaching ... at university". It was only in her second year of studying that she saw "a black person on campus", as a lecturer that she realised the possibility of becoming a lecturer. She was also aware that with her study choice (which included Speech and Drama), that she may be 
caste into stereotypical roles in theatre "given the racial context of our country" (at the time). This realisation was part of the reasons that "informed my decision to want to be a lecturer at university". She was also "driven by the fact that" there were very few "African, Black, Indian or Coloured" lecturers and the few that there were, "excited her" and were an "inspiration" to her. She worked with one of them as a "research assistant", and was "picking up whatever I could", in terms of developing her knowledge and research capacity, where after she pursued her Doctoral degree and secured an international scholarship.

\subsubsection{Accidental leadership to middle management}

Qualifications to the level of a Doctorate, at a time when many women and Black academics did not have doctorates, also facilitated the pathway of the few women with doctorates and the ability to carry themselves academically, almost automatically ending up in middle management positions. Participant A could not remember "consciously wanting to become a leader" but ended up "with leadership jobs in academic development because of the way that the field just works ... especially once I had a PhD". She was then invited to apply for a middle management position. This then also opened the pathway towards her senior management position, which she had also not planned. Participant $C$ also expressed that she "never really planned to go into a ... management and administrative role" but her position in middle management was rather "circumstantial", rather than something for which she had applied.

\section{Discussion}

The findings reflect that women are capable of leadership and that their ways of leadership form an integral part of the roles of responsibility that they play in society. The reflection of passion and caring, teamwork and service orientation are distinct character traits of the forms of leadership displayed by women. Muzvidziwa (2015) reflected on this as transformational leadership, a leadership form that goes to the core of addressing social injustices. There is a compelling argument in terms of addressing social injustices towards women and the role of women in society, through the re-imagining of leadership and decolonising of the construct leadership. The male-gendered character traits traditionally associated with leadership are challenged, as the journeys of the three women reflect. Within their journeys towards leadership, they consistently reflect passion for their chosen paths, though at times it is tinged with uncertainty and therefore is a "safe", more traditional path. Yet, on these paths, they express courage and determination, challenging the traditional and westernised constructs of leadership, through displaying inward courage and determination and arming themselves with qualifications, and identifying role models who affirm them, at a time when women were not necessarily expressly encouraged to do so. The qualities displayed facilitate a form of leadership that is inclusive, caring and cooperative in nature, unlike the traditional masculine forms that have dominated for decades. This form of transformational leadership compels us to re-imagine leadership and to deconstruct what it means to be a leader in a period of transformation within our HEls. Decolonisation of ideology that valorises western forms of thought, knowledge and disciplines of leadership are contrasted with an inclusive, caring and service orientated approach. Factors that contributed to these leadership qualities cannot neatly be boxed into psychological or cultural respectively, but intertwine. This is reflected in the themes as identified, such as family responsibility (cultural) and self-doubt (psychological).

As previously indicated, culture plays an enormous role on decisions individuals make, and this is reflected in the women's experiences. Findings confirm that women still come through 
the traditional women's career-path (teaching, in this case), which was often the choice based on work-family balance or uncertainty. The journeys reflect that women make choices about careers, in academia as well as in leadership. Factors such as family responsibility influence these decisions, and whereas there is a view that women should not doubt their abilities, and be more affirming within themselves, there is a view that women have been given false choices. Both views speak to a life-style continuum that women face decisions on family responsibility, career choices, etcetera, and then again reflects the perpetuation of the status quo of society's traditional view of women's roles and responsibilities in the family. Family responsibility is still viewed as primarily a women's role rather than an equal and collective and possibly a negotiated one, giving opportunities for career development as part of a healthy, balanced work-family environment.

All participants expressed that decisions had to be made, and that women needed to be more confident and unapologetic in making these. Role models (in the form of men and women) at the meso-level facilitated advancement. The effect of positive role models was a re-affirmation of their abilities to transcend barriers, as well as a new sense of self. This, coupled with intrinsic motivation (often driven by passion or uncertainty as previously indicated, and therefore the decision to continuously learn), led to opportunities in middlemanagement positions. It was also their caring and service-oriented leadership style, that saw them being persuaded into middle management. The journeys also reflect the non-linear and non-chronological pathways often followed by women through, amongst others, decisions around family-work balance, uncertainty around career-pathing, positive role models and passion for higher education.

\section{Conclusions}

As previously indicated, in re-imagining higher education leadership, women's ways of leadership should form part of the discourse of re-creating the construct leadership. Women's forms of leadership are transformational in addressing social injustices and valorise qualities that traditional constructs of leadership have devalorised. Decolonisation of the construct leadership, demands the re-imaging of leadership, and valorising qualities and values as reflected in women's ways of leading. Transformation in leadership is intricately linked with deconstructing a colonialist view of leadership, as masculine in nature, based on western traditions and thought. The valorisation of masculine characteristics, perpetuating gendered cultures within the higher education space, has to be deconstructed in favour of a paradigm that valorises men and women's ways of leadership. This forms part of transformation and decolonisation of leadership towards social justice; bringing the voices of women into the leadership space in a more equitable manner.

Though the common elements of career choice (teaching) suggest a conformity in terms of women's career choices as reflected in literature, this is not necessarily for the reasons as cited in literature (work-family balance), but rather points to a period of uncertainty in the career phases of the three women. It suggests the need for mentoring and support structures during the earlier years of career-pathing, and may assist in broadening the scope of women's choices. Role models and mentoring has been a key factor in driving men's successful careerpathing, and women also need to reflect on their roles as role models and mentors, and building support networks, as well-established within male-networks. Socialisation amongst women, inclusive of men, demands an active approach towards actively lobbying for the inclusion of women in leadership. There have been arguments for the implementation of a 
framework towards professional development of women, which is cognisant of women's nonlinear and non-chronological pathway. Within this, capacity-building programmes should be cognisant of factors influencing women's ability to participate in leadership and recognise constraints as highlighted. Implementation should be embedded in policy in relation to gender equity, as this is key to the empowerment of women towards leadership. Importantly, it cannot be argued that there are not sufficiently qualified women in these positions (in HEls), but it cannot be ignored that women must come out of their comfort zone and also challenge the status quo.

\section{Recommendations}

The paper argues that the construct of leadership should be re-imagined and re-created in terms of valorising women and men's forms of leadership, towards challenging the gendered nature of the higher education environment. Women's ways of leadership should be recognised through the process of deconstructing and reconstructing the colonialist traditions of leadership. This should occur within a framework that reflects the non-linear, non-chronological pathways that women often follow, guided by Policy on Gender Equity (as proposed in the Moodly-Toni framework). Part of this process includes identifying role models who strongly influence and affirm women. This framework should be established at sectoral as well as institutional level and should facilitate the re-construction of leadership (as part of the transformation and decolonisation process), and may affect the psychological and cultural factors that influence future generations of leadership within the sector, and beyond. Men and women alike are responsible for the re-creation of leadership towards social justice. Women have to be bold enough to take charge of their own career-pathing and being an equal voice in the decolonisation of the construct of leadership towards the valorisation of qualities embracing women and men's ways of knowing and doing, towards transformational leadership addressing social injustices. Engagement on this is foregrounded on a paradigm shift and a reconstituting of the psyche, embracing an ethical transformational framework.

\section{References}

Badat, S. 2009. Theorising institutional change: Post-1994: South African higher education. Studies in Higher Education, 34(4), 455-467. https://doi.org/10.1080/03075070902772026

Becker, A. 2017. Rage, loss and other footpaths: Subjectification, decolonisation and transformation in higher education. Transformation in Higher Education, 2519-5638.

Bulick, N. \& Frey, S. 2017. The working woman in higher education: reflections of the past, hope for the future. Reference Reviews, 31(2), 1-7. https://doi.org/10.1108/RR-08-2016-0201

Chanana, K. 2013. Leadership for women's equality and empowerment in higher education. India International Centre Quarterly, 39(3/4) (winter 2013-spring 2013), 81-84.

Grimshaw, P. \& Francis, R. 2014. Academic women and research leadership in twentiethcentury Australia. In: J Damousi, K Rubenstein \& M Tomsic (Eds.). Diversity in leadership. ANU Press. https://doi.org/10.22459/DL.11.2014.11

Hammond, K. 2006. More Than a Game: A Critical Discourse Analysis of a Racial Inequality Exercise in Japan. TESOL Quarterly, 40(3), 545-571. https://doi.org/10.2307/40264543

Jansen, J. 2017. As by fire: The end of the South African university. Tafelberg: Cape Town, South Africa. 
Moodly, A. 2015. Gender equity in South African higher education leadership: Where are we twenty years after democracy? Journal of Social Sciences, 42(3), 229-238. https://doi.org/10 $.1080 / 09718923.2015 .11893410$

Moodly, A. \& Toni, N. 2015a. Women's access towards higher education leadership: Where are the role models? Journal of Social Sciences, 45(1), 45-52.

Moodly, A. \& Toni. N. 2015b. Women's voices of and on leadership in higher education. https://doi.org/10.20853/31-3-917 Paper presented at the Global Research and International Services (GRDS) 7th International Conference on Teaching, Education and Learning (ICTEL), 10-11 October 2015. Pointe aux Piments, Mauritius.

Moodly, A. \& Toni, N. 2017. Accessing Higher Education leadership: A framework for women's professional development. South African Journal of Higher Education, 31 (3), 138-153.

Muzvidziwa, I. 2015. Women educational leaders and the empowerment of others. Journal of Sociology and Social Anthropology, 6(3), 365-376. https://doi.org/10.1080/09766634.2015.118 85676

Nguyen, T.L.H. 2013. Barriers to and facilitators of female Deans' career advancement in higher education: an exploratory study in Vietnam. Higher Education, 66(1), 123-138. https:// doi.org/10.1007/s10734-012-9594-4

Pillay, S. 2013. Decolonising the humanities. Available at https://mg.co.za/article/2013-04-05decolonising-the-humanities [Accessed 28 October 2017].

Republic of South Africa. 1996. White Paper No.3 on Higher Education Transformation. Pretoria: Government Printers.

Republic of South Africa. 2001. National Plan for Higher Education. Ministry of Education. Pretoria: Government Printers.

Republic of South Africa. 2013. Women Empowerment and Gender Equality Bill. National Assembly, Pretoria: South Africa.

Republic of South Africa. 2017. Statistical release-Mid-year population estimates (July). Pretoria: South Africa.

Shambare, R. 2011. MDGs and gender equity in higher education in South Africa. International Journal of Management and Innovation, 3(2):46-55.

Shevel, A. 2014. SA companies falling shy of gender quotas. Sunday Times. March 09:7. 